\title{
Victoria Reid, André Gide and Curiosity
}

\section{Monia Mezzetti}

\section{(2) OpenEdition}

\section{Journals}

\section{Edizione digitale}

URL: http://journals.openedition.org/studifrancesi/6413

DOI: $10.4000 /$ studifrancesi.6413

ISSN: 2421-5856

\section{Editore}

Rosenberg \& Sellier

\section{Edizione cartacea}

Data di pubblicazione: 1 novembre 2010

Paginazione: 584

ISSN: 0039-2944

\section{Notizia bibliografica digitale}

Monia Mezzetti, «Victoria Reid, André Gide and Curiosity», Studi Francesi [Online], 162 (LIV | III) | 2010

online dal 30 novembre 2015, consultato il 09 janvier 2021. URL: http://journals.openedition.org/ studifrancesi/6413 ; DOI: https://doi.org/10.4000/studifrancesi.6413

\section{Questo documento è stato generato automaticamente il 9 janvier 2021.}

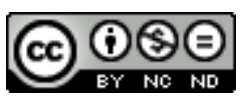

Studi Francesi è distribuita con Licenza Creative Commons Attribuzione - Non commerciale - Non opere derivate 4.0 Internazionale. 


\title{
Victoria Reid, André Gide and Curiosity
}

\author{
Monia Mezzetti
}

\section{NOTIZIA}

VICTORIA REID, André Gide and Curiosity, Amsterdam-New York, Rodopi, 2009 («Faux titre», 340), pp. 316.

1 Nei Faits divers (1930) Gide sosteneva che «la curiosité est un des ressorts de notre activité [...] le plus méconnu et le moins étudié». Oggi sarebbe quindi piacevolmente stupito dal numero di studi nel frattempo condotti sull'argomento, tra cui, il più recente, quello di Victoria Reid, dove, previa una dettagliata panoramica sulla bibliografia critica degli ultimi trentacinque anni (pp.25-32), viene intrapresa un'analisi del corpus narrativo e memoriale dell'autore (compresi gli scritti preparatori di suo pugno) in chiave psicoanalitica, in base alle teorie di Melanie Klein. Queste, infatti, più di altre, si dimostrano adatte alla comprensione di determinati tratti comportamentali di Gide, dei suoi orientamenti sessuali e dei suoi interessi, interpretandoli come sintomatici di una (presunta) mancata elaborazione in età infantile della cosiddetta "posizione depressiva", in cui il bambino dovrebbe costruirsi un'immagine "positiva" della madre. In quest'ottica, le principali forme di curiosità ("sessuale", "scientifica" e "scrittoria", che in questa stessa sequenza sono proposte dalla scansione interna del saggio) rappresenterebbero, da un lato, delle manifestazioni di tipo nevrotico-ossessivo dell'irrisolta operazione mentale e affettiva e, dall'altro, una forma di difesa inconsciamente attuata nei confronti dell'alterata immagine materna.

2 Il primo capitolo, il più esteso e documentato, traccia le coordinate della "sexual incuriosity» di Gide tanto per la dimensione erotica di tipo eterosessuale quanto per il soggetto femminile (dalla corporeità alla sensibilità), avvalendosi a tale scopo sia delle ammissioni dell'autore al riguardo, sia della testimonianza dei suoi contemporanei (principalmente Martin du Gard) e delle prerogative di alcuni personaggi in questo 
senso esemplificativi (scopofilia, feticismo, pederastia, frigidità); questa sezione, inoltre, senza ignorare il condizionamento sessuofobico derivante dall'educazione protestante, ma coerentemente con l'approccio metodologico prescelto, imputa l'incuriosity dello scrittore essenzialmente al vissuto psichico. Il capitolo successivo prende in esame invece l'interesse di Gide per varie discipline, dalle scienze naturali a quelle sociali, prospettandole sempre come reazioni a un disagio interiore, mentre l'ultimo si sofferma sul ruolo compensativo della scrittura e della lettura rispetto al senso di vuoto susseguente alla scomparsa della madre. Dopo la conclusione, completano il volume un glossario dei termini psicanalitici (pp. 277-281) e una ricca e aggiornata bibliografia (pp. 284-307). 